\title{
Mild pituitary phenotype in 3- and 12-month-old Aip-deficient male mice
}

\author{
Anne-Lise Lecoq1,2,*, Philippe Zizzari3,*, Mirella Hage1,2, Lyvianne Decourtye4, \\ Clovis Adam5, Say Viengchareun',2, Johannes D Veldhuis ${ }^{6}$, Valérie Geoffroy7, \\ Marc Lombès',2, Virginie Tolle ${ }^{3}$, Anne Guillou ${ }^{8}$, Auli Karhu9 ${ }^{9}$, Laurent Kappeler ${ }^{4}$, \\ Philippe Chanson',2,10 and Peter Kamenický1,2,10
}

\author{
${ }^{1}$ Institut National de la Santé et de la Recherche Médicale (Inserm) U1185, Le Kremlin-Bicêtre, France \\ 2Université Paris-Sud, Faculté de Médecine Paris-Sud, Le Kremlin-Bicêtre, France \\ IInserm U894, Centre de Psychiatrie et Neurosciences, Université Paris Descartes, Sorbonne Paris Cité, Paris, France \\ 4Sorbonne Universités, Univ Paris 06 UMRS 938, Inserm U938, CDR Saint-Antoine, Paris, France \\ ${ }^{5}$ Assistance Publique-Hôpitaux de Paris, Service d'Anatomie et Cytologie Pathologiques, Hôpital Bicêtre, \\ Le Kremlin Bicêtre, France \\ ${ }^{6}$ Department of Medicine, Endocrine Research Unit, Mayo School of Graduate Medical Education, \\ Clinical Translational Science Center, Mayo Clinic, Rochester, Minnesota, USA \\ 7Inserm U1132, Hôpital Lariboisière, Université Paris Diderot, Sorbonne Paris Cité, Paris, France \\ 8Unité Mixte de Recherche-5203, Centre National de la Recherche Scientifique, Institut de Génomique \\ Fonctionnelle, Montpellier, France \\ 9Department of Medical Genetics, Genome-Scale Biology Research Program Biomedicum, University of Helsinki, \\ Helsinki, Finland \\ ${ }^{10}$ Assistance Publique-Hôpitaux de Paris, Service d'Endocrinologie et des Maladies de la Reproduction, \\ Hôpital Bicêtre, Le Kremlin Bicêtre, France \\ *(A-L Lecoq and P Zizzari contributed equally to this work)
}

Correspondence should be addressed to P Kamenický Email peter.kamenicky@bct.aphp.fr

\begin{abstract}
Germline mutations in the aryl hydrocarbon receptor-interacting protein (AIP) gene predispose humans to pituitary adenomas, particularly of the somatotroph lineage. Mice with global heterozygous inactivation of $\mathrm{Aip}\left(\mathrm{Aip}^{+/-}\right)$also develop pituitary adenomas but differ from AIP-mutated patients by the high penetrance of pituitary disease. The endocrine phenotype of these mice is unknown. The aim of this study was to determine the endocrine phenotype of $\mathrm{Aip}^{+/-}$mice by assessing the somatic growth, ultradian pattern of GH secretion and IGF1 concentrations of longitudinally followed male mice at 3 and 12 months of age. As the early stages of pituitary tumorigenesis are controversial, we also studied the pituitary histology and somatotroph cell proliferation in these mice. $\mathrm{Aip}^{+/-}$mice did not develop gigantism but exhibited a leaner phenotype than wild-type mice. Analysis of GH pulsatility by deconvolution in 12-month-old Aip ${ }^{+/-}$mice showed a mild increase in total GH secretion, a conserved GH pulsatility pattern, but a normal IGF1 concentration. No pituitary adenomas were detected up to 12 months of age. An increased ex vivo response to GHRH of pituitary explants from 3-month-old Aip ${ }^{+/}$- mice, together with areas of enlarged acini identified on reticulin staining in the pituitary of some $\mathrm{Aip}^{+/-}$mice, was suggestive of somatotroph hyperplasia. Global heterozygous Aip deficiency in mice is accompanied by subtle increase in GH secretion, which does not result in gigantism. The absence of pituitary adenomas in 12-month-old $\mathrm{Aip}^{+/-}$mice in our experimental conditions demonstrates the important phenotypic variability of this congenic mouse model.
\end{abstract}

\section{Key Words}

- growth hormone

- AIP

- aryl hydrocarbon receptor-interacting protein

- pituitary adenoma

- germline mutations http://joe.endocrinology-journals.org DOI: 10.1530/JOE-16-0190
๑๐ 2016 Society for Endocrinology Printed in Great Britain
Published by Bioscientifica Ltd
Journal of Endocrinology (2016) 231, 59-69 


\section{Introduction}

Since 2006, mutations in the AIP (aryl hydrocarbon receptor-interacting protein) gene have been known to predispose humans to pituitary adenomas (Vierimaa et al. 2006). Heterozygous mutations are found in $20 \%$ of familial isolated pituitary adenomas (FIPA) (Beckers et al. 2013) and in 3-4\% of sporadic pituitary adenomas (Lecoq et al. 2015). AIP-mutated patients mainly develop growth hormone (GH)- and prolactin (PRL)-secreting tumors. They also have a younger age at diagnosis, a predominance of macroadenomas and frequent resistance to medical treatments. The AIP-mutated giants are predominantly males (Daly et al. 2010, Cazabat et al. 2012). Predisposition to pituitary adenoma due to AIP mutation is also characterized by low penetrance (about 20\%) (Williams et al. 2014).

AIP is considered to be a tumor suppressor gene (Leontiou et al. 2008) with many molecular interacting partners (Trivellin \& Korbonits 2011). AIP protein is ubiquitously expressed and is physiologically present in somatotroph and lactotroph cells, in association with the secretory vesicles, suggesting a potential role in hormone secretion. However, the precise molecular mechanisms by which AIP mutations lead to pituitary adenomas remain unclear (Lecoq et al. 2016). Homozygous Aip knockout mice are not viable and die during embryonic development with various cardiovascular malformations (Lin et al. 2007). Only one mouse model with global heterozygous inactivation of Aip $\left(\mathrm{Aip}^{+/-}\right)$has been reported to develop pituitary adenomas (Raitila et al. 2010), but it exhibits many differences with the pituitary tumor susceptibility caused by AIP germline mutations in humans. In particular, the pituitary disease in $\mathrm{Aip}^{+/-}$mice was shown to have $100 \%$ penetrance and to be similarly frequent in males and females. Furthermore, although GH immunostaining is found in most of these mouse tumors (88\%), no phenotypic manifestation of GH excess has been reported (Raitila et al. 2010).

The aim of this study was to further characterize the endocrine phenotype of $A \mathrm{ip}^{+/-}$mice by assessing the somatic growth, pulsatile GH secretion and IGF1 concentrations of male mice followed longitudinally at 3 and 12 months of age. This timing was chosen to investigate their growth phenotype and hormonal status, along with the possible age dependency of pituitary tumor development (Raitila et al. 2010). We found that, despite mild GH hypersecretion and an increased response to GHRH, $\mathrm{Aip}^{+/-}$mice did not develop gigantism and had normal IGF1 levels. As the early stages of pituitary tumorigenesis are controversial
(Melmed 2011, Villa et al. 2011), we also studied the pituitary histology and somatotroph cell proliferation in the same mice. Surprisingly, in contrast to the original description (Raitila et al. 2010), the mice did not develop pituitary adenomas, but pituitary hyperplasia was detected in some $\mathrm{Aip}^{+/-}$mice, and may represent an early step in the development of pituitary adenomas.

\section{Materials and methods}

\section{Animals}

$A i p^{+/-}$mice were generated as described previously (Raitila et al. 2010). Heterozygous (Aipt+-) male and wild-type (WT) female mice were bred according to the Guide for the Care and Use of Laboratory Animals published by the National Institutes of Health (NIH Publication No. 85-23, revised 1996). Experiments were conducted during the light phase in 3- and 12-month-old $\mathrm{Aip}^{+/-}$male mice and WT littermate controls. All mice were kept on the same initial C57BL/6Rcc background and belonged to generations F16+1-3. Offspring was genotyped by PCR amplification of tail DNA, as described previously (Raitila et al. 2010) and confirmed with RT-qPCR and Western blot analyses (Supplementary Fig. 1, see section on supplementary data given at the end of this article). The mice were housed in a temperaturecontrolled colony room with a 12:12 h light:darkness cycle $(0700 \mathrm{~h}$ to $1900 \mathrm{~h})$. All studies have been performed with access to food and tap water ad libitum.

The animal facility was approved (no. C94-043-12) by the Ministère de l'Agriculture, France. All procedures were carried out in accordance with the European Communities Council Directive and were approved by the local ethics committee CAPSud (no. 2013-071).

\section{Assessment of total body weight and body length}

Mice were weighed at 3, 7 and 12 months of age. Repeated measurements of the naso-anal distance were made on awake mice at 3 and 7 months of age. 5 consecutive pictures of each mouse maintained in extension were taken and analyzed with ImageJ software (http://rsbweb.nih.gov/ij/). At 12 months of age, mice were anesthetized with isoflurane before measuring the naso-anal distance.

\section{Body composition and fat mass measurements}

Body composition was assessed at 3 and 12 months of age using dual-energy X-ray absorptiometry (DEXA; PIXImus2,

Published by Bioscientifica Ltd. 
Lunar, Madison, WI, USA). Each mouse was anesthetized for the duration of the procedure $(5 \mathrm{~min})$ by exposure to isoflurane via a nose cone. Each mouse was then placed on the scanner bed in the prone position, with the limbs and tail stretched away from the body. An ultrahigh-resolution mode $(0.18 \times 0.18 \mathrm{~mm})$ was used. Based on the attenuation of two energy levels, the system provides quantitative data on the fat tissue content, lean tissue content and total tissue mass within a region of interest (ROI). One scan per mouse was performed and analyzed with PIXImus software (2.10, GE/Lunar). The head was excluded from the calculation by applying a manual ROI. A shape was scanned daily to monitor the stability of the measurements, according to the manufacturer's instructions.

The same mice used for DEXA were decapitated for perifusion experiments. The epididymal white adipose depots located around each testis were carefully separated from the epididymis. Part of the inguinal white adipose tissue was then dissected at the level of the lower leg (inner side). Both tissues were weighed with an analytical balance. Fat pads from the epididymal region were considered to represent intra-abdominal adipose tissue, and fat pads from the inguinal compartment subcutaneous adipose tissue. To compare the relative adipose tissue mass, individual tissue weights were normalized by dividing the absolute tissue weight by the total body weight of each animal.

\section{Repeated blood sampling for GH assay}

Repeated blood sampling was performed in longitudinally followed male mice at 3 and 12 months of age. Mice were first habituated to single housing 1 week before the beginning of the experiment and handled to minimize stress. Four microliters of venous whole blood were obtained from the tail vein every $10 \mathrm{~min}$ for 6 consecutive hours. Samples were collected between $1000 \mathrm{~h}$ and $1600 \mathrm{~h}$, following the established guidelines (Steyn et al. 2011), except that the tail was sectioned $1 \mathrm{~h}$ before blood collection and a cardboard tube was not used to handle the mouse during sampling. Blood samples were collected and homogenized in $116 \mu \mathrm{L}$ of GH enzyme immunoassay (EIA) buffer (PBS, 0.05\% Tween) in 96-well plates kept on ice during the whole procedure, then stored at $-20^{\circ} \mathrm{C}$ until analysis.

\section{GH release from pituitary explants}

Experiments were conducted on 3- and 12-month-oldmice, starting between $0930 \mathrm{~h}$ and $1030 \mathrm{~h}$. Mice were decapitated and blood samples were collected from arterial blood vessels of the neck and centrifuged at $4^{\circ} \mathrm{C}$ for $5 \mathrm{~min}$ at $300 \mathrm{~g}$. Supernatants were collected and stored at $-20^{\circ} \mathrm{C}$ until hormone assays (IGF1 and leptin).

For perifusion, the pituitary was rapidly dissected out, placed in a perifusion chamber (vol, $0.4 \mathrm{~mL}$ ) and superfused at a rate of $0.1 \mathrm{~mL} / \mathrm{min}$ with oxygenated DMEM/HAM'S F-12 medium (PAA, Velizy-Villacoublay, France) containing $0.1 \%$ bovine serum albumin. After a 120-min equilibration period, effluents were collected every $5 \mathrm{~min}$. Mouse GHRH $\left(10^{-7} \mathrm{M}\right.$, Sigma-Aldrich) and somatostatin-14 (10-7 M, H-1490, Bachem, Bubendorf, Switzerland) were added to the medium during 15-min periods. Samples were frozen until GH determination as described in the 'Hormone assays' section below.

\section{Hormone assays}

Whole-blood GH concentrations were determined by EIA as described previously (Steyn et al. 2011), using antibodies listed in Supplementary Table 1 . Values are reported in terms of rGH-RP2. The detection limit was $0.038 \mathrm{ng} / \mathrm{mL}$ and the intraassay and interassay coefficients of variation were $3.2 \%$ and $<8.75 \%$, respectively. Values are expressed as $\mathrm{GH}$ plasma concentrations.

IGF1 concentrations in plasma were determined with a Mouse/Rat IGF-1 ELISA kit (80-INSMSU-E01, ALPCO, Eurobio, Les Ulis, France) and leptin levels with a Mouse Leptin ELISA kit (EZML-82K, Merck Millipore, Molsheim, France) following the manufacturers' instruction manuals. IGF1 and leptin were assayed serially in both 3- and 12-month-old mice. Prolactin concentrations in plasma were determined by ultrasensitive ELISA assay as described previously (Guillou et al. 2015).

\section{Analysis of GH pulsatility}

GH pulsatility was deciphered by deconvolution analysis using the established parameters (Liu et al. 2009). Measurements included the number and mass of secretory bursts (mass per pulse, MPP) and basal, pulsatile and total GH secretion. The orderliness of GH secretion was calculated by approximate entropy (ApEn) analysis as described previously (Veldhuis et al. 2001).

\section{Gene expression analyses}

Gene expression was studied by real-time RT-PCR in 3- and 12-month-old male mice. After sacrifice,

Published by Bioscientifica Ltd 
the hypothalamus and pituitary were quickly dissected out and stored at $-80^{\circ} \mathrm{C}$ until mRNA extraction with TriReagent (Life Technologies) was performed according to the manufacturer's recommendations. cDNA was obtained by reverse transcription of $1 \mu \mathrm{g}$ of total RNA. Quantitative real-time PCR (qRT-PCR) was performed using the Fast SYBR Green Master Mix (ABI, Applied Biosystems, Life Technologies) on a StepOnePlus System (Applied Biosystems, Life Technologies). Standards and samples were amplified in duplicate. The internal control gene was $\beta$-actin. Gene expression is reported as the ratio of attomoles of the specific gene to attomoles of $\beta$-actin. The primers for $\beta$-actin, Ghrh, Srih, Gh and Ghrh-r are shown in Supplementary Table 2.

\section{Immunofluorescence and immunohistochemistry}

Pituitaries from 3- and 12-month-old $\mathrm{Aip}^{+/-}$and WT male mice were fixed in $4 \%$ paraformaldehyde, embedded in gelatin (Sigma) and frozen. Cryosections $(18 \mu \mathrm{m})$ were fixed on Superfrost Plus slides. Immunofluorescence was performed using the VECTOR M.O.M. Immunodetection Kit FMK-2201 (Vector Laboratories, Eurobio) and the Dako Biotin Blocking System (X0590, Dako). Slides were incubated with a rabbit anti-GH antibody 1:20,000 (AFP5641801, NIDDK, National Hormone and Peptide Program, (Supplementary Table 1)) and a mouse anti-Ki67 antibody 1:400 (550609, BD Pharmingen, Le Pont de Claix, France, (Supplementary Table 1)), followed by donkey antirabbit IgG H\&L DyLight 550 (ab98499, Abcam, (Supplementary Table 1)) and the M.O.M. biotinylated anti-mouse antibody. Slides were mounted with DAPI VECTASHIELD medium (Vector Laboratories), and micrographs were acquired in identical conditions for light intensity, charge-coupled device (CCD) image acquisition and signal integration with a X60 oil objective using an Olympus BX612 fluorescence microscope and DP71 CCD camera.

Normal and hyperplastic pituitary tissues were identified by Gordon and Sweet's silver staining for reticulin. Pituitary hyperplasia was defined as a conserved but thinner and scarcer reticulin fiber network compared with normal pituitary, together with acini expansion. In addition, hematoxylin and eosin staining of the pituitaries from 3- to 12-monthold $\mathrm{Aip}^{+/-}$and WT male mice and 21- to 24-month-old $A i p^{+/-}$and WT female mice was performed to analyze the histopathological features.

\section{Statistical analyses}

Results are expressed as means \pm standard error of the mean (s.E.м.). Differences between groups were analyzed with the nonparametric Mann-Whitney test or by chisquare test (Prism software, GraphPad). A $P$ value below 0.05 was considered to denote statistical significance $\left({ }^{*} P<0.05 ;{ }^{* *} P<0.01 ;{ }^{* *} P<0.001\right)$.

\section{Results}

\section{Somatic growth of $\mathrm{Aip}^{+/-}$mice}

As $\mathrm{Aip}^{+/-}$mice are reportedly prone to GH-secreting pituitary adenomas, we first explored the growth phenotype in longitudinally followed mice at 3, 7 and 12 months of age (Fig. 1). Body weight was higher in $\mathrm{Aip}^{+/-}$ mice than in WT littermates at 3 months $(28.5 \pm 0.65 \mathrm{~g}$ vs $26 \pm 0.54 \mathrm{~g}, P=0.0071)$ and 7 months $(33.9 \pm 0.68 \mathrm{~g}$ vs $31.7 \pm 0.62 \mathrm{~g}, P=0.034)$ but not at 12 months. In contrast, the naso-anal length was not different, confirming that $\mathrm{Aip}^{+/-}$mice do not exhibit gigantism but suggesting their body composition is nonetheless affected.

\section{Changes in body composition in Aip Ap $^{+/}$mice}

We performed DEXA scans in 3- and 12-month-old mice (Fig. 2A, B and C). The excess body weight in 3-monthold $\mathrm{Aip}^{+/-}$mice was associated with higher lean mass than in WT mice (lean mass normalized to body weight $79.6 \%$ vs $74.0 \%, P=0.0104$, Fig. $2 \mathrm{~A}$ ). Higher lean mass was also observed at the age of 12 months $(72.6 \%$ vs $69.3 \%, P=0.0386$ ). Fat mass normalized to body weight revealed lower adiposity in $\mathrm{Aip}^{+/-}$mice at 3 and 12 months

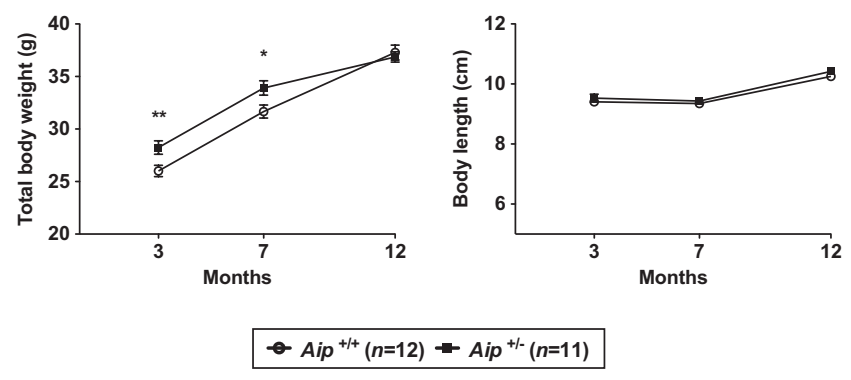

Figure 1

Body weight and naso-anal length of longitudinally followed $\mathrm{Aip}^{+/-}$and WT male mice. (A) Body weight was significantly higher in $\mathrm{Aip}^{+/-}$mice than in WT littermates at 3 and 7 months. (B) Naso-anal length was not different between $\mathrm{Aip}^{+/-}$and WT animals. Data are indicated as mean \pm S.E.M. The number of mice and their genotypes are indicated in the boxes below the graphs. ${ }^{*} P<0.05, * * P<0.01$.

Published by Bioscientifica Ltd 
A

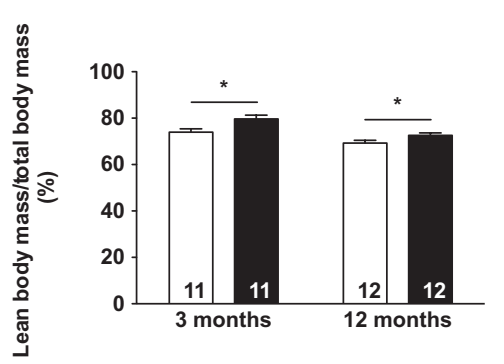

C

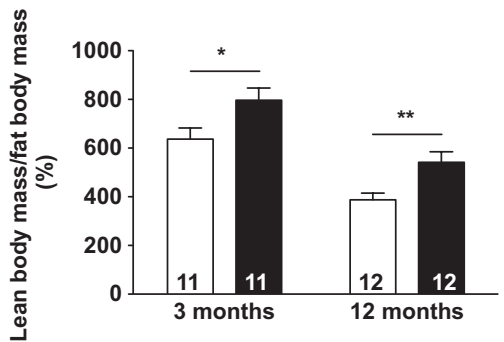

$\mathrm{E}$

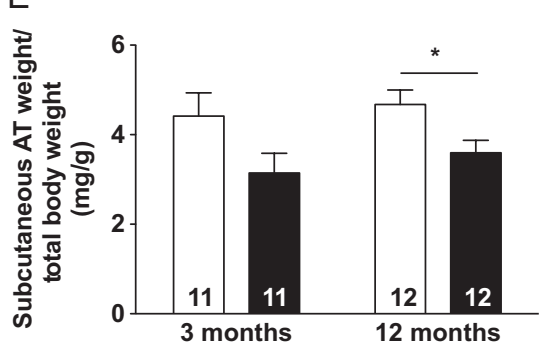

B

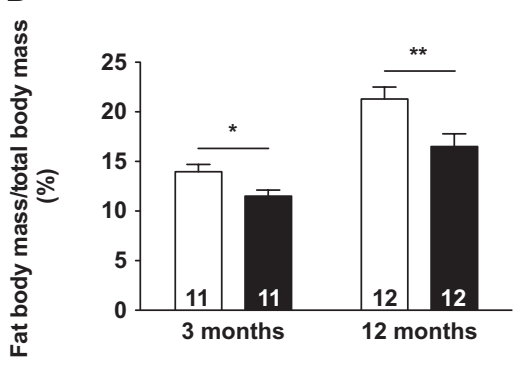

D

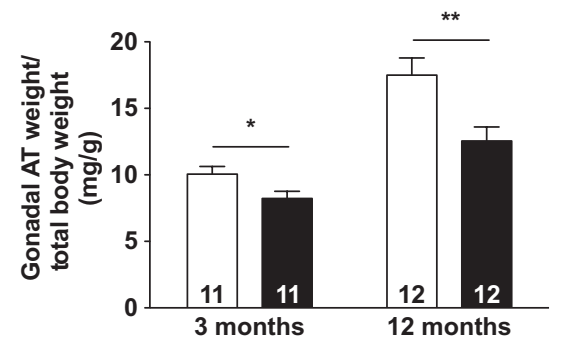

F

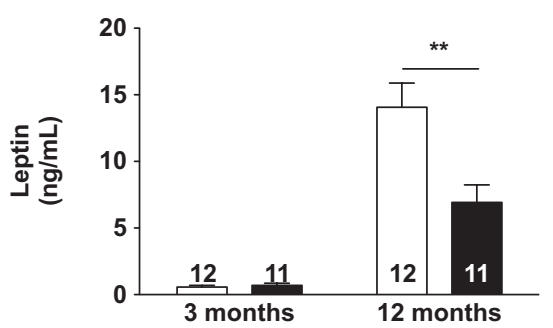

Figure 2

Body composition, WAT deposit weight and circulating leptin levels in $\mathrm{Aip}^{+/-}$and WT male mice at 3 and 12 months of age. (A) Lean mass normalized to body weight was higher in Aip $^{+/-}$mice than in WT animals at 3 and 12 months of age. (B) Fat mass normalized to body weight was lower in $\mathrm{Aip}^{+1-}$ mice than in WT littermates at 3 and 12 months of age. (C) The lean mass/fat mass ratio was higher in both 3- and 12-month-old Aip ${ }^{+/-}$mice than in WT mice. (D) Gonadal WAT deposit weight normalized to body weight was lower in Aip ${ }^{+/-}$mice than in WT mice at 3 and 12 months of age. (E) Subcutaneous inguinal WAT deposit mass normalized to body weight was lower in $\mathrm{Aip}^{+/-}$mice than in WT at 12 months of age. (F) Circulating leptin levels were lower in 12-month-old $\mathrm{Aip}^{+/-}$mice than in WT animals. Data are indicated as mean \pm s.E.M. The number of mice is indicated in the bar graph. $* P<0.05, * * P<0.01$.
(11.5\% vs $14.0 \%$, respectively, $P=0.0199$ and $16.5 \%$ vs 21.3\%, $P=0.0078$; Fig. 2B). Accordingly, the lean mass/fat mass ratio was higher in both 3- and 12-month-old $\mathrm{Aip}^{+/-}$ mice than in their WT counterparts (Fig. 2C).

Gonadal and inguinal white adipose tissue (WAT) depots were collected and weighed in 3- and 12-monthold animals (Fig. 2D and E). In keeping with the changes in body composition, gonadal adipose depots were smaller in 3- and 12-month-old $\mathrm{Aip}^{+/-}$mice than in WT animals $(P=0.0398$ at 3 months and $P=0.0036$ at 12 months, Fig. 2D). Similarly, inguinal adipose depots were smaller in 12-month-old $\mathrm{Aip}^{+/-}$mice than in WT mice $(P=0.0283$, Fig. $2 \mathrm{E})$. In 3 -month-old mice, the mass of inguinal adipose depots followed the same trend, but the difference did not reach statistical significance $(P=0.0754)$. Finally, circulating levels of leptin (Fig. 2F) were lower in 12-month-old $\mathrm{Aip}^{+/-}$mice than in WT mice $(P=0.0035)$, reflecting the lower whole-body fat mass.

\section{GH pulsatility and IGF1 concentrations in Aip Al- mice $^{+/}$}

Representative GH secretion profiles of WT and $\mathrm{Aip}^{+/-}$ mice at 3 and 12 months of age are illustrated in Fig. 3A, $\mathrm{B}, \mathrm{C}$ and D. In both genotypes, GH was secreted in ultradian manner, with secretory bursts occurring at about 3-h intervals. Results of deconvolution analysis are summarized in Table 1 and illustrated in Fig. 3E. As shown in Table 1, total, pulsatile and basal GH secretion rates declined significantly with age in both genotypes. The amount of GH secreted per burst was also lower in older animals. No significant difference in any of the studied parameters was found between the genotypes at 3 months of age. As shown in Table 1 and Fig. 3E, total $\mathrm{GH}$ secretion rate was higher in 12-month-old $\mathrm{Aip}^{+/-}$ mice than in their WT littermates $(P=0.0267)$. Pulsatile GH secretion showed a similar trend at 12 months $(P=0.0593$ vs WT), but the secretory pattern was not significantly modified.

Published by Bioscientifica Ltd 
A

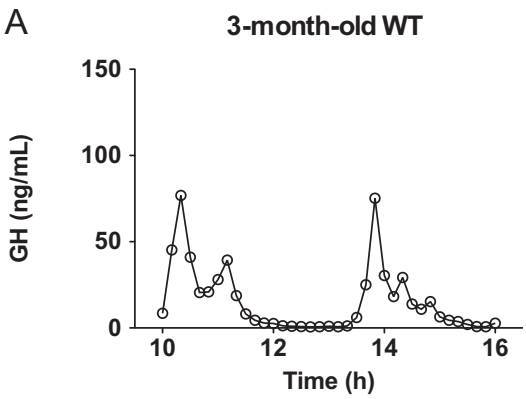

C

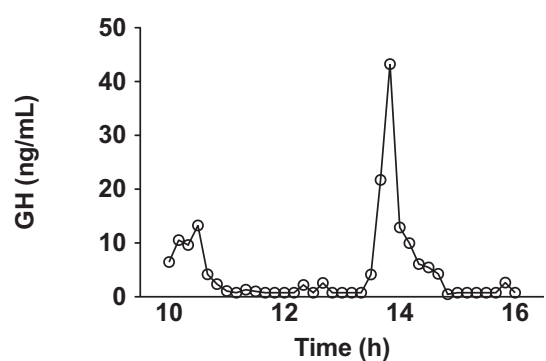

$\mathrm{E}$

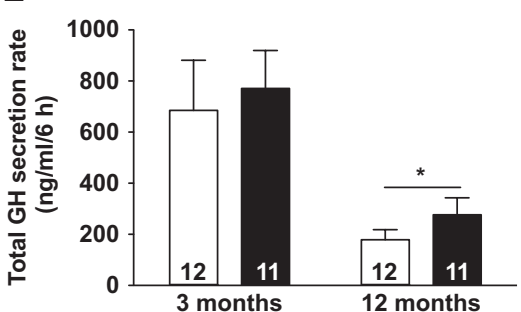

B

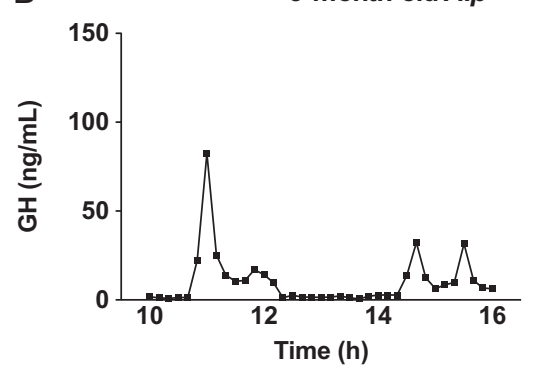

D

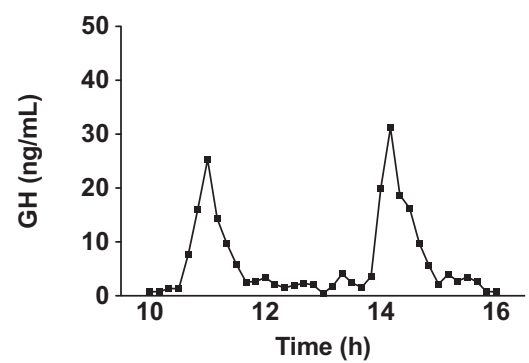

$\mathrm{F}$

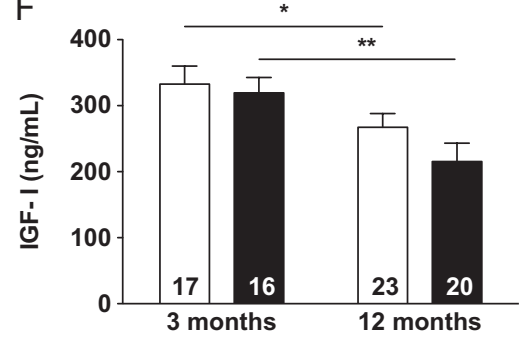

Figure 3

Pulsatile GH secretion and circulating IGF1 levels in $\mathrm{Aip}^{+/-}$and WT male mice at 3 and 12 months of age. (A-D) Representative 6-hour GH secretory profiles in Aip $^{+/-}$and WT mice at 3 (A-B) and 12 (C-D) months of age. Values are GH plasma concentrations. (E) Deconvolution analysis showed an increase in the total $\mathrm{GH}$ secretion rate in 12-month-old $\mathrm{Aip}^{+/-}$mice compared with that in WT littermates. (F) Circulating IGF1 levels fell with age but were similar in the two genotypes. Data are mean \pm S.E.M. The number of mice is indicated in the bar graph. ${ }^{*} P<0.05, * * P<0.01$.
This increase in GH secretion was not associated with higher circulating IGF1 levels (Fig. 3F) or with a negative feedback effect on hypothalamic Ghrh or Somatostatin transcript levels (data not shown).
Plasma prolactin concentrations were very low, decreased significantly with age $(P=0.0014)$ and were not different between genotypes (Supplementary Fig. 2).

Table 1 Deconvolution analysis of pulsatile GH secretion in longitudinally followed $\mathrm{Aip}^{+/-}$and wild-type male mice.

\begin{tabular}{l} 
GH pulsatility parameters \\
\hline Total secretion rate $(\mathrm{ng} / \mathrm{mL} / 6 \mathrm{~h})$ \\
Pulsatile secretion rate $(\mathrm{ng} / \mathrm{mL} / 6 \mathrm{~h})$ \\
Basal secretion rate $(\mathrm{ng} / \mathrm{mL} / 6 \mathrm{~h})$ \\
Mass of GH secreted/pulse $(\mathrm{ng} / \mathrm{mL})$ \\
Number of peaks/6h \\
Half-life slow (min) \\
ApEn
\end{tabular}

\begin{tabular}{c}
\hline 3-Mon \\
\hline Wild type $(n=12)$ \\
\hline $685.3 \pm 195.9$ \\
$480.9 \pm 114.4$ \\
$204.4 \pm 86.1$ \\
$138.5 \pm 36$ \\
$4.2 \pm 0.4$ \\
$8.6 \pm 1.1$ \\
$0.63 \pm 0.06$ \\
\hline
\end{tabular}

-Month-old mice

\begin{tabular}{clc} 
Aip $^{+/-}(n=11)$ & & $P$ \\
\cline { 1 - 1 } \pm 148.6 & & 0.4432 \\
$560.1 \pm 114$ & & 0.4432 \\
$211 \pm 55.1$ & & 0.5181 \\
$136.3 \pm 29.7$ & & 0.6842 \\
$4.7 \pm 0.5$ & & 0.2928 \\
$7.5 \pm 1.2$ & & 0.4413 \\
$0.68 \pm 0.05$ & & 0.3746
\end{tabular}

\begin{tabular}{ccccc}
\hline \multicolumn{3}{c}{ 12-Month-old mice } \\
\cline { 1 - 1 } Wild type $(n=12)$ & & Aip $^{+/-}(n=11)$ & & $P$ \\
\cline { 1 - 1 } $178.7 \pm 39.7^{* * *}$ & & $276.4 \pm 66.9^{* *}$ & & 0.0267 \\
$131.9 \pm 32.1^{* *}$ & & $201.5 \pm 48.4^{* *}$ & & 0.0593 \\
$46.8 \pm 8.7^{* * *}$ & & $74.9 \pm 19.3^{*}$ & & 0.2095 \\
$39.1 \pm 8.2^{*}$ & & $55.5 \pm 9.6^{*}$ & & 0.1171 \\
$3.5 \pm 0.3$ & & $3.6 \pm 0.3^{*}$ & & 0.8930 \\
$9.7 \pm 1$ & & $7.6 \pm 0.9$ & & 0.1321 \\
$0.56 \pm 0.06$ & & $0.48 \pm 0.05^{* *}$ & & 0.5962 \\
\hline
\end{tabular}

Samples were collected at 10-min intervals between 10:00 h and 16:00 h in the same mice at 3 and 12 months of age. Data are represented as mean \pm S.E.M. $P$ values for the genotype comparisons are indicated in the table. For the effect of aging in Aip ${ }^{+/}$and WT animals, $P$ values are indicated as follows: $* P<0.05, * * P<0.01, * * * P<0.001$.

ApEn, approximate entropy, measures the orderliness of GH secretion.

$\begin{array}{lr}\text { http://joe.endocrinology-journals.org } & \text { ○ } 2016 \text { Society for Endocrinology } \\ \text { DOI: } 10.1530 / J O E-16-0190 & \text { Printed in Great Britain }\end{array}$

Published by Bioscientifica Ltd 
A

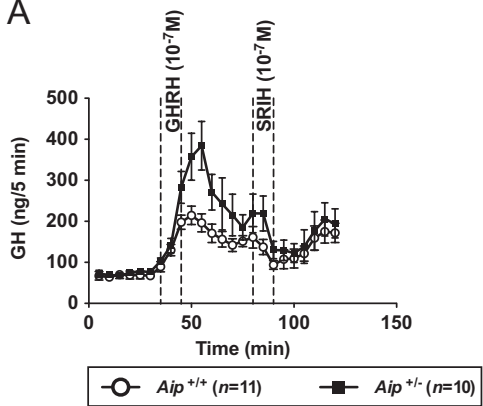

B

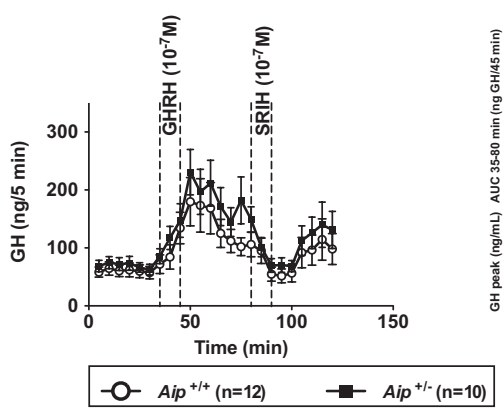

C

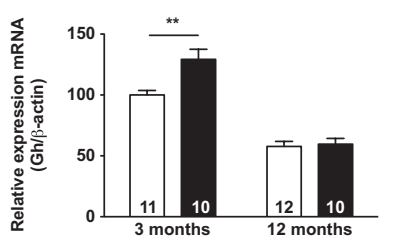

D

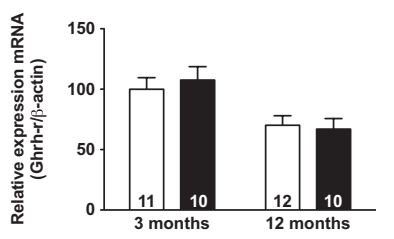

Figure 4

$\mathrm{GH}$ release from pituitary explants from 3 - and 12-month-old $\mathrm{Aip}^{+/-}$and WT mice, measured in basal conditions and after stimulation with $10^{-7} \mathrm{M} \mathrm{GHRH}$ or $10^{-7} \mathrm{M}$ somatostatin (SRIH); Gh and Ghrh-r expression measured by qRT-PCR in the same pituitaries. (A) At the age of 3 months, sensitivity to GHRH was significantly higher in $\mathrm{Aip}^{+/-}$than in WT mice, as shown by the GH secretion rate, the area under the curve (AUC) and the GH peak. Inhibition of GH secretion by SRIH was similar in the two genotypes. (B) At the age of 12 months, GH release did not differ between the genotypes in basal conditions, after GHRH stimulation, or after SRIH repression. (C) $G h$ transcript levels were higher in the pituitary of 3-month-old Aip ${ }^{+/-}$mice than in WT littermates. (D) Ghrh-r mRNA expression was not different between the genotypes at 3 or 12 months of age. Data are mean \pm S.E.M. For gene expression analyses, the data are expressed as a percentage of expression in WT mice at 3 months of age, arbitrarily set at $100 \%$. The number of mice and the genotype are indicated in the boxes below the graphs. ${ }^{*} P<0.05, * * P<0.01$.

\section{Basal and stimulated $\mathrm{GH}$ release from pituitary explants of Aip $^{+/-}$mice}

Given these subtle differences in pulsatile GH secretion, we further explored the somatotropic axis by measuring the capacity of ex vivo perifused pituitary fragments from 3- to 12-month-old mice to release GH in basal and stimulated conditions (Fig. 4A and B). At 3 months of age, the amount of GH released after stimulation with $10^{-7} \mathrm{M}$ GHRH was higher in $\mathrm{Aip}^{+/-}$mice than in WT mice (AUC $35-80 \mathrm{~min}=11127 \pm 1745$ vs $7421 \pm 671 \mathrm{ng}$ GH/45 min,
A

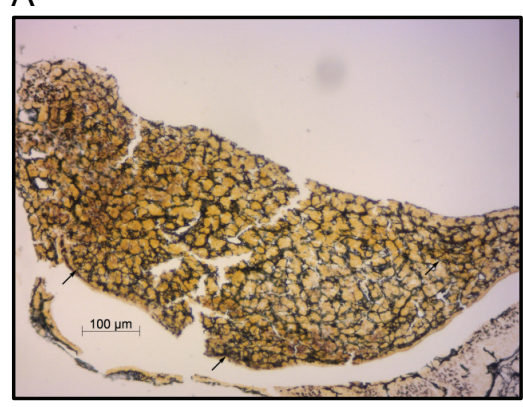

C

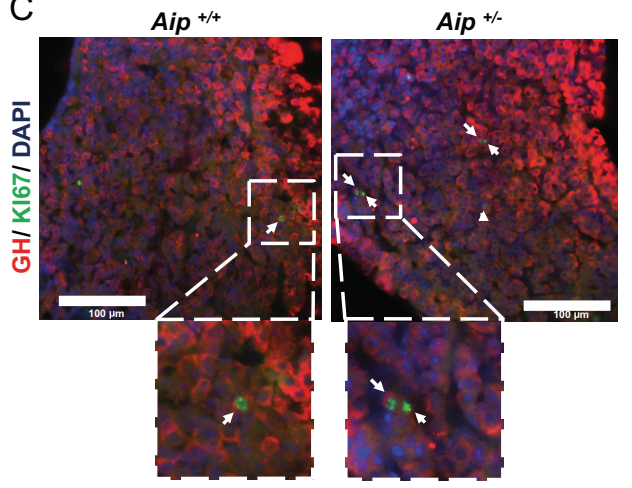

B

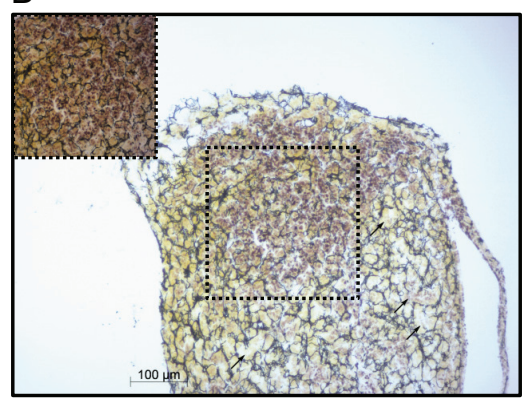

D

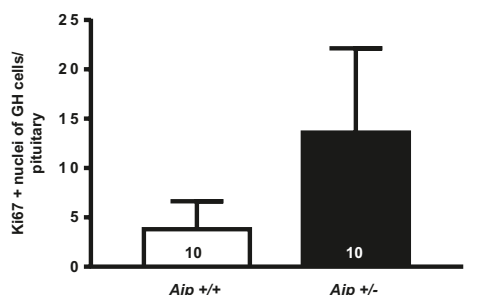

Figure 5

Pituitary histology in $\mathrm{Aip}^{+/-}$and WT mice (IHC and IF) and quantification of Ki67-positive somatotroph cells of $\mathrm{Aip}^{+/-}$and WT mice. (A) Reticulin staining of a normal adenohypophysis, as shown by IHC in a WT mouse. Black arrows show representative normal dense reticulin fiber networks. ( $\times 10$ magnification, size bars: $100 \mu \mathrm{m})$. (B) Reticulin staining of the pituitary of an Aip $^{+/-}$mouse. In areas of hyperplasia, the acini are expanded (black arrows; $\times 10$ magnification, size bars: $100 \mu \mathrm{m})$. The inset corresponds to $\mathrm{a} \times 20$ magnification of the region within the black square. Note the preserved but thinner and scarcer reticulin fiber network. (C) Representative IF images of Ki67 and GH immunostaining of WT mice (left panel) and $\mathrm{Aip}^{+/-}$mice (right panel) pituitaries. Nuclei were counterstained with DAPI. $\times 40$ magnification, white arrows, size bars: $100 \mu \mathrm{M}$. The insets show a magnification of representative nuclear staining for Ki67 and cytoplasmic staining for GH. (D) Quantification of Ki67-stained nuclei. Ki67-positive somatotroph cells tended to be more numerous in $\mathrm{Aip}^{+/-}$mice than in WT mice. Data are represented as mean \pm s.E.M. The number of mice is indicated in the bar graph. http://joe.endocrinology-journals.org DOI: 10.1530/JOE-16-0190
๑) 2016 Society for Endocrinology Printed in Great Britain 
A

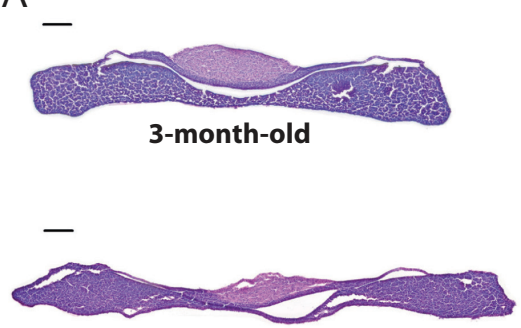

12-month-old

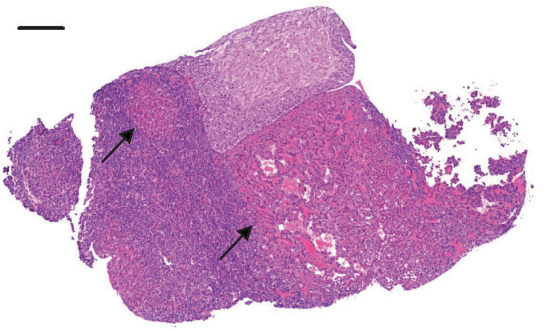

24-month-old
B

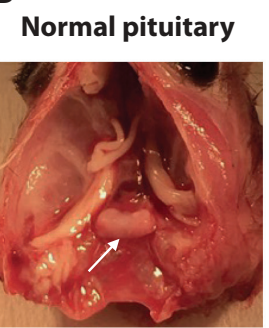

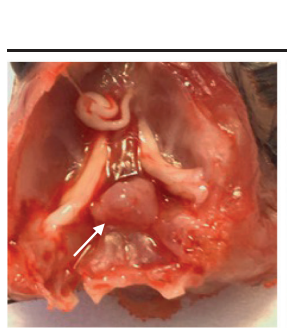

Macroadenomas

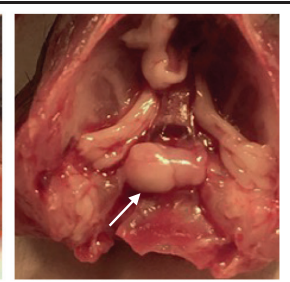

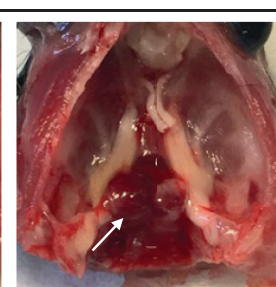

\section{Figure 6}

Pituitaries of 3- and 12-month old Aip $^{+/-}$male mice and of 21- to 24-month-old Aip ${ }^{+/-}$female mice. (A) Hematoxylin and eosin-stained frozen sections of pituitary glands of 3-and 12-month old Aip $^{+/-}$male mice (left upper and lower panels). No adenomas were detected. The right panel shows hematoxylin and eosin-stained paraffin-embedded sections of the pituitary gland of a 24-month-old Aip $^{+-}$female mouse with two adenomas (indicated by black arrows). Scale bars $=200 \mu \mathrm{m}$. (B) Examples of a normal pituitary gland (left panel) and 3 pituitary macroadenomas in 21- to 24-month-old $\mathrm{Aip}^{+/-}$female mice. The third adenoma is hemorrhagic. The pituitary gland or adenomas are depicted by a white arrow.
$P=0.0294 ; \quad G H \quad$ peak $=401 \pm 55.5$ vs $254 \pm 23.4 \mathrm{ng} / \mathrm{mL}$, $P=0.0294)$. By contrast, $\mathrm{GH}$ release after $10^{-7} \mathrm{M}$ somatostatin exposure did not differ between the genotypes. At 12 months, basal GH release as well as the responses to GHRH and somatostatin did not differ between $\mathrm{Aip}^{+/-}$and WT mice. In keeping with their greater sensitivity to GHRH, we observed higher $G h$ mRNA levels in the pituitary of 3 -month-old $\mathrm{Aip}^{+/-}$mice (1.3-fold vs WT, $P=0.0048$; Fig. 4C), whereas Ghrh-r expression did not differ (Fig. 4D).

\section{Proliferation of somatotroph cells in the Aip ${ }^{+/-}$pituitary}

Histological examination showed no pituitary adenomas in any of the 3- or 12-month-old $\mathrm{Aip}^{+/-}$or WT males analyzed. Modifications of the reticulin network indicative of pituitary hyperplasia were seen in 0 of $10 \mathrm{WT}$ mice (Fig. 5A) but in 3 of $10 \mathrm{Aip}^{+/-}$mice (Fig. 5B). Ki67 and $\mathrm{GH}$ costaining showed no foci of increased proliferation of either somatotroph cells or other pituitary cells in Aip $\mathrm{p}^{+/-}$mice. However, Ki67-positive somatotroph cells tended to be more numerous in $\mathrm{Aip}^{+/-}$mice than in WT mice (Fig. 5C).

The absence of pituitary tumors in 3- and 12-month-old males in our study brought us to explore the pituitaries in 21- to 24-month-old female mice. We observed macroadenomas during dissection (Fig. 6) in 5 of $18 \mathrm{Aip}^{+/-}$21- to-24-month-old female mice. However, 2 of 14 WT littermates of the same age also presented with macroscopically visible pituitary adenomas (NS).

\section{Discussion}

Ai $\mathrm{P}^{+/-}$mice are currently the only animal model of AIP-related pituitary tumorigenesis. The initial description of this model mentioned a very strong pituitary phenotype, with adenomas occurring in 100\% of mutants by the age of 15 months (Raitila et al. 2010). This strong penetrance contrasts with the human situation (Williams et al. 2014). To better characterize the endocrine phenotype of these mice, we examined the somatic growth and GH secretion of male mice at different ages.

We have focused our study only on males for two reasons. First, a male predominance is classically described among AIP mutation-positive patients with sporadic acromegaly (Daly et al. 2010, Lecoq et al. 2015), even though a recent study from a large international cohort did not observe the same results among the AIP mutation-positive familial cases (Hernández-Ramírez et al. 2015). Secondly, we preferred to avoid potential bias related to the well-known influence of sexual steroid variations during the estrous cycle on $\mathrm{GH}$ secretion in mice (Giustina \& Veldhuis 1998).

One major finding is that $A i p^{+/-}$mice do not develop gigantism. This is a major difference with human AIPrelated pituitary disease (Daly et al. 2010) and challenges the secretory nature of somatotroph adenomas previously shown by IHC in these mice (Raitila et al. 2010). However, even if their naso-anal length was normal, Ai $p^{+/-}$mice showed differences in their body weight and composition relative to their WT counterparts.

Published by Bioscientifica Ltd. 
GH plays an important role in the regulation of body composition, promoting a lean phenotype by increasing lipolysis in WAT and enhancing protein synthesis in muscle (Møller \& Jørgensen 2009). In humans, acromegaly leads to an increase in body water and lean body mass (Ikkos et al. 1954, O'Sullivan et al. 1994, Kamenický et al. 2014), associated with a reduction in body fat (Freda et al. 2008, Katznelson 2009). Similarly, giant bovine-GH transgenic mice (bGH) exhibit a lower body fat percentage, smaller WAT deposits and lower serum leptin levels (Berryman et al. 2004, Benencia et al. 2014). We found that Aip ${ }^{+/-}$mice exhibit a slightly enhanced total body weight at 3 and 7 months but not at 12 months of age. The increased lean mass of $\mathrm{Aip}^{+/-}$ mice could be related to body fluid retention (Ikkos et al. 1954, O'Sullivan et al. 1994, Kamenický et al. 2014), but we did not determine total body water. Fat mass increased with age in both $\mathrm{Aip}^{+/-}$and WT mice but to a lesser extent in the mutants, possibly explaining the similar total body weights of 12-month-old mutant and WT mice. Leptin plasma levels increased with age in both genotypes, as described in rats (Igel et al. 1996, Li et al. 1997) but were lower in Aip ${ }^{+/-}$mice. Altogether, these changes in body composition could be related to GH hypersecretion.

Here we show, for the first time, that $\mathrm{Aip}^{+/-}$males display a slight increase in total GH secretion at the age of 12 months, with a conserved GH pulsatility pattern. We used a waveform-independent deconvolution method that can discriminate between acromegalic and normal subjects. Acromegaly is classically characterized by an increased GH pulse frequency, higher basal GH secretion rates and higher ApEn values, suggesting more irregular GH concentration profiles than those in normal subjects (Hartman et al. 1994). Nevertheless, in keeping with our studies of $\mathrm{Aip}^{+/-}$mice, recent data suggest that the complex rhythm and age dependency of $\mathrm{GH}$ secretion are both preserved in patients with acromegaly (Ribeiro-Oliveira et al. 2013). However, the biological significance of this subtle increase in total GH secretion is questionable, as it does not result in elevated IGF1 plasma concentrations. Similar observations have recently been reported in mice lacking both somatostatin and cortistatin, which have high GH levels but a normal growth rate and normal IGF1 levels suggestive of partial GH resistance (PedrazaArévalo et al. 2015).

The observed changes in body composition due to global heterozygous inactivation of Aip in this mouse model could also be explained by a role of AIP in WAT homeostasis, energy expenditure and/or hypothalamic control of food intake. AIP is ubiquitously expressed, but its physiological functions in specific tissues are poorly known (Trivellin \& Korbonits 2011, Beckers et al. 2013).

Another major finding of this study is that male $A i p^{+/-}$mice do not develop pituitary adenomas up to the age of 12 months. Macroadenomas were observed in a few 21- to 24-month-old mice but without any differences between the genotypes. The discrepancy between the high penetrance of pituitary disease in the initial description of this mouse model (Raitila et al. 2010) and the lack of spontaneous tumors in 3- and 12-month-old males in our study, which used genetically identical mice from the same source (as confirmed by genotyping, RT-qPCR and Western blot, Supplementary Fig. 1), was unexpected. One possibility is that environmental factors interfere with pituitary tumorigenesis (Crabbe et al. 1999), especially as the privileged molecular partner of AIP is the xenobiotic receptor AhR (aryl hydrocarbon receptor) (Carver et al. 1998, Lecoq et al. 2016). Alternatively, the phenotypic discrepancy could be related to greater genetic homogeneity due to additional backcrosses since the initial publication (F16+1-3). Of note, the reported prevalence of pituitary adenomas in WT mice in the initial publication of Raitila and coworkers is unexpectedly high. The histological analysis in this study identified pituitary adenomas in approximately $40 \%$ of WT mice at the age of $15-18$ months. Most of these adenomas showed prolactin immunoreactivity. However, prolactin secretion was not studied (Raitila et al. 2010). It would be interesting to know whether this strong pituitary phenotype (Raitila et al. 2010) is maintained after several years of backcrosses in the original environment. Similar to our observation, the penetrance of pituitary adenomas in AIP-mutated families is low, but subtle hormonal abnormalities may exist in some AIP mutation carriers who have not yet developed pituitary adenomas (Naves et al. 2007, Williams et al. 2014).

The mild GH hypersecretion observed here in 12-month-old $\mathrm{Aip}^{+/-}$male mice, in the absence of a clear endocrine phenotype and pituitary adenomas, suggests that AIP deficiency may be associated with earlier stages of pituitary tumorigenesis such as pituitary hyperplasia, which could precede pituitary tumor development (Melmed 2011). We postulated that somatotroph cell hyperplasia could result in GHRH hypersensitivity. This was confirmed ex vivo in 3-month-old $\mathrm{Aip}^{+/-}$mice by an

Published by Bioscientifica Ltd. 
enhanced GH response of isolated pituitary explants to GHRH, but no such effect was seen in 12-month-old $A i p^{+/-}$mice. In parallel, by means of IHC, we observed areas of hyperplastic tissue in a few $\mathrm{Aip}^{+/-}$mice at 3 and 12 months of age, with a tendency to more prevalent Ki67 immunostaining in $A i^{+/-}$somatotroph cells. Thus, the increased GHRH response in 3-month-old $\mathrm{Aip}^{+/-}$mice could be related to pituitary hyperplasia in some animals and/or to a particular organization of the GH cell network (Bonnefont et al. 2005) caused by AIP deficiency in other animals. As Aip may be a tumor suppressor gene, this somatotroph hyperplasia could result from the loss of the first Aip allele and might represent a tumor-initiating event (Melmed 2011). However, multiple environmental factors are no doubt involved in tumorigenesis in AIPmutated somatotroph cells (Välimäki et al. 2015).

In conclusion, global heterozygous inactivation of Aip in mice does not result in gigantism or clinical acromegaly. Further, $A i p^{+/-}$mice did not develop pituitary adenomas up to the age of 12 months, but Aip deficiency was accompanied by subtle changes in the somatotroph axis and by somatotroph hyperplasia. The lack of pituitary adenoma development in our experimental conditions demonstrates the important phenotypic variability of this congenic animal model of AIP-related pituitary tumorigenesis, resembling the inconstant penetrance of pituitary disease in AIP-mutated humans.

\section{Supplementary data}

This is linked to the online version of the paper at http://dx.doi.org/10.1530/ JOE-16-0190.

\section{Declaration of interest}

The authors declare that there is no conflict of interest that could be perceived as prejudicing the impartiality of the research reported.

\section{Funding}

This work was supported by grants from Inserm, Université Paris-Sud. A $L L$ was the recipient of a fellowship from the French Endocrine Society (Société Française d'Endocrinologie), of a Poste d'Accueil INSERM (ITMO Cancer-Plan cancer) and a grant from Association de Recherche contre le Cancer (ARC). P K was the recipient of a Contrat d'Interface Inserm 2014.

\section{Author contribution statement}

$A \mathrm{~L} L, \mathrm{P} Z, \mathrm{P} C$ and $\mathrm{P} K$ contributed to the conception and design of the research; $A K$ provided the mice; $A L L, P Z, M H, L D, S V, V G, V G, M C$, $L K$ and $P K$ performed the experiments; $A L L, P Z, M H, J D V, V G, L K$ and

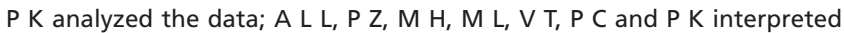
the results of the experiments; $A L L, P Z$ and $P K$ prepared the figures; $A L L$ and $P K$ drafted the manuscript; $A L L, P Z, S V, M L, L K, P C$ and $P K$ edited and revised the manuscript; $A L L, P Z, M H, S V, M L, L K, P C$ and $\mathrm{PK}$ approved the final version of the manuscript.

\section{Acknowledgements}

The authors thank Prof. Yves Le Bouc and Maud Clemessy (Inserm U938, Hôpital Saint-Antoine, Paris, France) for his helpful comments on IGF1 assays and technical assistance in pituitary immunofluorescence, Dr Agnès Martin (CNRS, IGF, Montpellier) for her help in prolactin assays, Dr Nadine Binart and Dr Valérie Bernard (Inserm U1185, Le Kremlin-Bicêtre, France) for their help with mouse dissection, Virginie Grybek (Inserm U1169, 94276 Le Kremlin-Bicêtre, France) for technical assistance in assays and Dr Larbi Amazit and Luc Outin for their help with the IF pictures.

\section{References}

Beckers A, Aaltonen LA, Daly AF \& Karhu A 2013 Familial isolated pituitary adenomas (FIPA) and the pituitary adenoma predisposition due to mutations in the aryl hydrocarbon receptor interacting protein (AIP) gene. Endocrine Reviews 34 239-277. (doi:10.1210/er.2012-1013)

Benencia F, Harshman S, Duran-Ortiz S, Lubbers ER, List EO, Householder L, Alnaeeli M, Liang X, Welch L, Kopchick JJ, et al. 2014 Male bovine GH transgenic mice have decreased adiposity with an adipose depot-specific increase in immune cell populations. Endocrinology en20141794. (doi:10.1210/en.2014-1794)

Berryman DE, List EO, Coschigano KT, Behar K, Kim JK \& Kopchick JJ 2004 Comparing adiposity profiles in three mouse models with altered GH signaling. Growth Hormone \& IGF Research 14 309-318. (doi:10.1016/j.ghir.2004.02.005)

Bonnefont X, Lacampagne A, Sanchez-Hormigo A, Fino E, Creff A, Mathieu M-N, Smallwood S, Carmignac D, Fontanaud P, Travo P, et al. 2005 Revealing the large-scale network organization of growth hormone-secreting cells. PNAS 102 16880-16885. (doi:10.1073/ pnas.0508202102)

Carver LA, LaPres JJ, Jain S, Dunham EE \& Bradfield CA 1998 Characterization of the Ah receptor-associated protein, ARA9. Journal of Biological Chemistry 273 33580-33587. (doi:10.1074/ jbc.273.50.33580)

Cazabat L, Bouligand J, Salenave S, Bernier M, Gaillard S, Parker F, Young J, Guiochon-Mantel A \& Chanson P 2012 Germline AIP mutations in apparently sporadic pituitary adenomas: prevalence in a prospective single-center cohort of 443 patients. Journal of Clinical Endocrinology and Metabolism 97 E663-E670. (doi:10.1210/jc.2011-2291)

Crabbe JC, Wahlsten D \& Dudek BC 1999 Genetics of mouse behavior: interactions with laboratory environment. Science $\mathbf{2 8 4}$ 1670-1672. (doi:10.1126/science.284.5420.1670)

Daly AF, Tichomirowa MA, Petrossians P, Heliövaara E, Jaffrain-Rea M-L, Barlier A, Naves LA, Ebeling T, Karhu A, Raappana A, et al. 2010 Clinical characteristics and therapeutic responses in patients with germ-line AIP mutations and pituitary adenomas: an international collaborative study. Journal of Clinical Endocrinology and Metabolism 95 E373-E383. (doi:10.1210/jc.2009-2556)

Freda PU, Shen W, Heymsfield SB, Reyes-Vidal CM, Geer EB, Bruce JN \& Gallagher D 2008 Lower visceral and subcutaneous but higher intermuscular adipose tissue depots in patients with growth hormone and insulin-like growth factor I excess due to acromegaly. Journal of Clinical Endocrinology and Metabolism 93 2334-2343. (doi:10.1210/ jc.2007-2780)

Giustina A \& Veldhuis JD 1998 Pathophysiology of the neuroregulation of growth hormone secretion in experimental animals and the human. Endocrine Reviews 19 717-797. (doi:10.1210/edrv.19.6.0353)

Guillou A, Romanò N, Steyn F, Abitbol K, Le Tissier P, Bonnefont X, Chen C, Mollard P \& Martin AO 2015 Assessment of lactotroph axis functionality in mice: longitudinal monitoring of PRL secretion by ultrasensitive-ELISA. Endocrinology 156 1924-1930. (doi:10.1210/ en.2014-1571)

Hartman ML, Pincus SM, Johnson ML, Matthews DH, Faunt LM, Vance ML, Thorner MO \& Veldhuis JD 1994 Enhanced basal and 
disorderly growth hormone secretion distinguish acromegalic from normal pulsatile growth hormone release. Journal of Clinical Investigation 94 1277-1288. (doi:10.1172/JCI117446)

Hernández-Ramírez LC, Gabrovska P, Dénes J, Stals K, Trivellin G, Tilley D, Ferraù F, Evanson J, Ellard S, Grossman AB, et al. 2015 Landscape of familial isolated and young-onset pituitary adenomas: prospective diagnosis in AIP mutation carriers. Journal of Clinical Endocrinology and Metabolism 100 E1242-E1254. (doi:10.1210/ jc.2015-1869)

Igel M, Kainulainen H, Brauers A, Becker W, Herberg L \& Joost HG 1996 Long-term and rapid regulation of ob mRNA levels in adipose tissue from normal (Sprague Dawley rats) and obese (db/db mice, fa/fa rats) rodents. Diabetologia 39 758-765. (doi:10.1007/s001250050508)

Ikkos D, Luft R \& Sjogren B 1954 Body water and sodium in patients with acromegaly. Journal of Clinical Investigation 33 989-994. (doi:10.1172/ JCI102977)

Kamenický P, Mazziotti G, Lombès M, Giustina A \& Chanson P 2014 Growth hormone, insulin-like growth factor-1, and the kidney: pathophysiological and clinical implications. Endocrine Reviews $\mathbf{3 5}$ 234-281. (doi:10.1210/er.2013-1071)

Katznelson L 2009 Alterations in body composition in acromegaly. Pituitary 12 136-142. (doi:10.1007/s11102-008-0104-8)

Lecoq A-L, Kamenický P, Guiochon-Mantel A \& Chanson P 2015 Genetic mutations in sporadic pituitary adenomas - what to screen for? Nature Reviews. Endocrinology 11 43-54. (doi:10.1038/nrendo.2014.181)

Lecoq A-L, Viengchareun S, Hage M, Bouligand J, Young J, Boutron A, Zizzari P, Lombes M, Chanson P \& Kamenicky P 2016 AIP mutations impair AhR signaling in pituitary adenoma patients fibroblasts and in GH3 cells. Endocrine-Related Cancer 23 433-443. (doi:10.1530/ ERC-16-0041)

Leontiou CA, Gueorguiev M, van der Spuy J, Quinton R, Lolli F, Hassan S, Chahal HS, Igreja SC, Jordan S, Rowe J, et al. 2008 The role of the aryl hydrocarbon receptor-interacting protein gene in familial and sporadic pituitary adenomas. Journal of Clinical Endocrinology and Metabolism 93 2390-2401. (doi:10.1210/jc.2007-2611)

Li H, Matheny M, Nicolson M, Tümer N \& Scarpace PJ 1997 Leptin gene expression increases with age independent of increasing adiposity in rats. Diabetes 46 2035-2039. (doi:10.2337/diab.46.12.2035)

Lin BC, Sullivan R, Lee Y, Moran S, Glover E \& Bradfield CA 2007 Deletion of the aryl hydrocarbon receptor-associated protein 9 leads to cardiac malformation and embryonic lethality. Journal of Biological Chemistry 282 35924-35932. (doi:10.1074/jbc.M705471200)

Liu PY, Keenan DM, Kok P, Padmanabhan V, O’Byrne KT \& Veldhuis JD 2009 Sensitivity and specificity of pulse detection using a new deconvolution method. American Journal of Physiology: Endocrinology and Metabolism 297 E538-E544. (doi:10.1152/ajpendo.00071.2009)

Melmed S 2011 Pathogenesis of pituitary tumors. Nature Reviews. Endocrinology 7 257-266. (doi:10.1038/nrendo.2011.40)

Møller N \& Jørgensen JOL 2009 Effects of growth hormone on glucose, lipid, and protein metabolism in human subjects. Endocrine Reviews 30 152-177. (doi:10.1210/er.2008-0027)

Naves LA, Daly AF, Vanbellinghen J-F, Casulari LA, Spilioti C, Magalhães AV, Azevedo MF, Giacomini LA, Nascimento PP, Nunes RO, et al. 2007 Variable pathological and clinical features of a large Brazilian family harboring a mutation in the aryl hydrocarbon receptor-interacting protein gene. European Journal of Endocrinology 157 383-391. (doi:10.1530/EJE-07-0533)

O'Sullivan AJ, Kelly JJ, Hoffman DM, Freund J \& Ho KK 1994 Body composition and energy expenditure in acromegaly. Journal of Clinical Endocrinology and Metabolism 78 381-386. (doi:10.1210/ jcem.78.2.8106626)

Pedraza-Arévalo S, Córdoba-Chacón J, Pozo-Salas AI, L-López F, de Lecea L, Gahete MD, Castaño JP \& Luque RM 2015 Not so giants: mice lacking both somatostatin and cortistatin have high GH levels but show no changes in growth rate or IGF-1 levels. Endocrinology 156 1958-1964. (doi:10.1210/en.2015-1132)

Raitila A, Lehtonen HJ, Arola J, Heliövaara E, Ahlsten M, Georgitsi M, Jalanko A, Paetau A, Aaltonen LA \& Karhu A 2010 Mice with inactivation of aryl hydrocarbon receptor-interacting protein (Aip) display complete penetrance of pituitary adenomas with aberrant ARNT expression. American Journal of Pathology 177 1969-1976. (doi:10.2353/ajpath.2010.100138)

Ribeiro-Oliveira A, Abrantes MM \& Barkan AL 2013 Complex rhythmicity and age dependence of growth hormone secretion are preserved in patients with acromegaly: further evidence for a present hypothalamic control of pituitary somatotropinomas. Journal of Clinical Endocrinology and Metabolism 98 2959-2966. (doi:10.1210/ jc.2013-1581)

Steyn FJ, Huang L, Ngo ST, Leong JW, Tan HY, Xie TY, Parlow AF, Veldhuis JD, Waters MJ \& Chen C 2011 Development of a method for the determination of pulsatile growth hormone secretion in mice. Endocrinology 152 3165-3171. (doi:10.1210/en.2011-0253)

Trivellin G \& Korbonits M 2011 AIP and its interacting partners. Journal of Endocrinology 210 137-155. (doi:10.1530/JOE-11-0054)

Välimäki N, Demir H, Pitkänen E, Kaasinen E, Karppinen A, Kivipelto L, Schalin-Jäntti C, Aaltonen LA \& Karhu A 2015 Whole-genome sequencing of growth hormone $(\mathrm{GH})$ - secreting pituitary adenomas. Journal of Clinical Endocrinology and Metabolism 100 3918-3927. (doi:10.1210/jc.2015-3129)

Veldhuis JD, Johnson ML, Veldhuis OL, Straume M \& Pincus SM 2001 Impact of pulsatility on the ensemble orderliness (approximate entropy) of neurohormone secretion. American Journal of Physiology: Regulatory, Integrative and Comparative Physiology 281 R1975-R1985.

Vierimaa O, Georgitsi M, Lehtonen R, Vahteristo P, Kokko A, Raitila A, Tuppurainen K, Ebeling TML, Salmela PI, Paschke R, et al. 2006 Pituitary adenoma predisposition caused by germline mutations in the AIP gene. Science 312 1228-1230. (doi:10.1126/ science.1126100)

Villa C, Lagonigro MS, Magri F, Koziak M, Jaffrain-Rea M-L, Brauner R, Bouligand J, Junier MP, Di Rocco F, Sainte-Rose C, et al. 2011 Hyperplasia-adenoma sequence in pituitary tumorigenesis related to aryl hydrocarbon receptor interacting protein gene mutation. Endocrine-Related Cancer 18 347-356. (doi:10.1530/ERC-11-0059)

Williams F, Hunter S, Bradley L, Chahal HS, Storr HL, Akker SA, Kumar AV, Orme SM, Evanson J, Abid N, et al. 2014 Clinical experience in the screening and management of a large kindred with familial isolated pituitary adenoma due to an aryl hydrocarbon receptor interacting protein (AIP) mutation. Journal of Clinical Endocrinology \& Metabolism 99 1122-1131. (doi:10.1210/ jc.2013-2868)

Received in final form 28 July 2016

Accepted 8 August 2016

Accepted Preprint published online 8 August 2016 http://joe.endocrinology-journals.org

DOI: $10.1530 / \mathrm{JOE}-16-0190$
() 2016 Society for Endocrinology Printed in Great Britain
Published by Bioscientifica Ltd. 